\title{
Study on mitigation of ammonia volatilization loss in urea through adsorbents
}

\author{
Angamuthu Manikandan ${ }^{1 *}$ and Kizhaeral S. Subramanian ${ }^{2}$ \\ ${ }^{1}$ ICAR-Central Institute for Cotton Research, Nagpur - 440010 (Maharashtra), INDIA \\ ${ }^{2}$ Department of Nano Science and Technology, Tamil Nadu Agricultural University, Coimbatore- 641003 (Tamil \\ Nadu), INDIA \\ *Corresponding author. E-mail: poonamani223@gmail.com
}

Received: August 8, 2016; Revised received: February 3, 2017; Accepted: April 7, 2017

\begin{abstract}
Volatilized ammonia loss (VAL) and toxicity are major disadvantages on urea amendment. In order to mitigate, slow (or) controlled release urea based fertilizers are prepared with low cost materials. Therefore, micro and nano-sized adsorbents such as zeolite, biochar were impregnated with urea @1:1 ratio for fertilizer formulations. The objective of the study was to evaluate the VAL rate. To study the effect of soil texture, incubation experiment on two different soils of Tamil Nadu (Typic Haplustalf and Vertic Ustropepts) with 4 physically mixed, 4 fabricated, conventional urea and control without urea determined. Fertilizer formulations were surface applied @ $250 \mathrm{~kg}$ $\mathrm{N}$ ha ${ }^{-1}$ and assessed the VAL rate for 16 days. The trapped ammonia was observed with colour change from pink to greenish and titrated with diluted sulfuric acid. Initial 3 days VAL rate was high on urea, physically mixed adsorbent fertilizers than urea impregnated fertilizers and colour change was observed on every 4-6 h of both soils. In contrast, the urea impregnated fertilizers had colour change after $9-10 \mathrm{~h}$ regardless of adsorbent and soils. The fabricated fertilizer observed VAL rate on gradual with low quantity on $\mathrm{T}_{5^{-}}$- Zeourea (13.5 days, 15.1 days) $\mathrm{T}_{6}$ - Nano-zeourea (15.5 days, 16 days), $T_{9}$ - Biourea ( 7.5 days, 7.1 days) and $T_{10^{-}}$Nano-biourea (9 days, 9.7 days) than $T_{2^{-}}$Urea (5.5 days, 4.6 days) of Alfisols and Inceptisols respectively. Cumulative VAL rate percentage was low on $\mathrm{T}_{5}$ - Zeourea (30 $\%$, $34 \%)$, $\mathrm{T}_{6}$ - Nano-zeourea (28 \%, $\left.29.3 \%\right) \mathrm{T}_{9}$ - Biourea (39 \%, $\left.41.5 \%\right)$ and $\mathrm{T}_{10^{-}}$Nano-biourea $(36 \%, 37.5 \%)$ of Alfisols and Inceptisols, respectively on comparison with other fertilizer type. It is concluded that the surface amendment of physically mixed fertilizers not influenced any change on both soils. Urea impregnation influenced on days and cumulative VAL percentage. Our study elucidates that micro and nano porous adsorbents are potential substrate to reduce VAL rate of urea in both soils.
\end{abstract}

Keywords: Biochar, Incubation, Micro and Nano formulations, Volatilized Ammonia Loss, Zeolite

\section{INTRODUCTION}

Today, the country's $78 \%$ of total $\mathrm{N}$ met through straight fertilizer-urea with self-sufficient production units. Urea raw material requirements are fulfilled by indigenous resources $(\approx 80 \%)$ like natural gas, naptha and crude oil. Prevailing low price with subsidized rate to farmers increased the use of urea under cultivation. Several field experimental results reported that 33-35 $\%$ of nitrogen use efficiency (NUE) under upland conditions and inadvertent application wastes 65-67\% which pollutes soil and water system. Soil ( $\mathrm{pH}$, Texture, Organic matter, $\mathrm{CaCO}_{3}$, Moisture, Temperature) and environmental factors (Rainfall, Relative Humidity) influence the hydrolysis (2-3 days) and $\mathrm{N}$ transformations and its major disadvantages are nitrification, ammonia volatilization and toxicity in environments (Cameron et al., 2013). Urease activity is major concern and it hydrolyzes the urea ranging from 20-30 $\mu \mathrm{g}$ of $\mathrm{N} \mathrm{g} \mathrm{soil}{ }^{-1} \mathrm{~h}^{-1}$. Its amendment increases soil $\mathrm{pH}$ and temperature influences ammonia volatilization $17-67 \%$. Urea amendment with pre sowing, soil incor- poration $(0.05 \mathrm{~m})$, pre-rain or irrigation, split dose and different approaches recorded minimum reduction VAL rate on different soils (Bishop and Manning, 2010). Different potential urease inhibitors like agrotain, phenyl phosphoro diamidate (PPD), pine oleoresin, chitosan and iron pyrite were used for delaying the hydrolysis and reduced ammonia volatilization (Blaise and Prasad 1995; Rui et al., 2010). Its low availability urged to find different options.

Another view is that there is a modified policy on nutrient based subsidy and permitted to sale with more than $10 \%$ of MRP on fertilizers interested on commercial for novel fertilizer production. Hence, the production of different slow / controlled release fertilizers like neem coated urea, boronated urea and sulphur coated urea increased. Its use drastically reduces the ammonia volatilized loss up to 60 percent (Fan et al., 2011; Stafanato et al., 2013) and its high cost is detrimental to farmers. Hence, the low cost available resources could be used as substrate. Many studies described that the use of zeolite forms, (clinoptilolite, philipsite, 
mordenite, chabazite) and biochar forms (charcoal and activated carbon) are potential sources to remove ammonia from the aquacultural wastes, poultry houses, municipal wastes, sewage sludge, dairy effluent and synthetic effluent waste water (Zabochnicka and Malinska, 2010.). Sago water and acidic water mixed use on fertilizer preparation also reduces the ammonia volatilization. (Latifah et al., 2011). Acidified biochar amendment with urea (Nascimento et al., 2013) and oxidized charcoal improves its efficiency (Paiva et al., 2012). Zeolite and biochar are cheaper and cost effective resources with high availability and were promoted with considerable interest as amendment along with conventional fertilizers. Special structural properties like mesopores, nanoporous and its ion exchange property could be effectively used to reduce ammonia loss. Nitrogen enrichment and retention on adsorbents is viable approach for to mitigate VAL. Therefore, basic principles of nano science is used in the synthesis of novel fertilizers with above adsorbents such as ball milling, nano-casting template, hydrothermal crystallization, homogeneous precipitation, liquid crystal templating mechanism, intercalation, impregnation, encapsulation, simple immersion techniques and other novel processes. (Manikandan et al., 2013; Manikandan and Subramanian, 2014). Under the above assumptions current study will assess the VAL rate and its loss per cent of different urea formulations on both soil types.

\section{MATERIALS AND METHODS}

Micro and nano porous zeolite (clintoptilolite) adsorbents were procured from GM Chemicals and Singhal Chemicals, Allahabad respectively. Another source of adsorbent, i.e., biochar is produced through slow pyrolysis $\left(>350^{\circ} \mathrm{C}\right)$ of Prosopis hard wood and their size is reduced through ball milling method as per standard protocol (Manikandan et al., 2013). Ball milled bio- char is referred as size reduced biochar (SRB). Micro and nano sized adsorbents (zeolite and biochar) was impregnated with urea @ 1:1 ratio on weight basis by hydro-thermal crystallization process (Chang, 1997). Four different nitrogenous fertilizers with varying nitrogen content were fabricated which were referred as zeourea $(18.5 \% \mathrm{~N})$, nanozeourea $(28 \% \mathrm{~N})$, biourea $(16.3 \% \mathrm{~N})$ and nanobiourea $(18.8 \% \mathrm{~N})$. Fabricated fertilizers (urea impregnated adsorbents) nitrogen loading efficiency was validated with semi quantitative (SEM-EDAX) and titration method as well (Tandon, 2005). Two different (Light and heavy) textured soils of Tamil Nadu State were selected for this study (2011 -12). Furrow slice (15 cm deep) soils were taken from on-farm experimental field of Northern Block, ND-6, Agricultural Research Station, Bhavanisagar [Alfisols, Loamy sand, Irugur series, Typic Haplustalf] and Eastern Block, B-36, Tamil Nadu Agricultural University, Coimbatore [Inceptisol, Blacksoil, Periyanaicken Palayam series, Vertic Ustropepts]. Both physical and chemical properties of the soil were determined with standard methods of analysis (Table 1).

In order to determine the VAL rate and cumulative percentage incubation experiment were evaluated with ten treatments viz., $\mathrm{T}_{1}$ - Control, $\mathrm{T}_{2}$ - Urea, $\mathrm{T}_{3}$ - Zeolite + urea, $\mathrm{T}_{4^{-}}$Nanozeolite + urea, $\mathrm{T}_{5^{-}}$zeourea, $\mathrm{T}_{6^{-}}$ Nanozeourea, $\mathrm{T}_{7^{-}}$- Biochar+ urea, $\mathrm{T}_{8^{-}} \mathrm{SRB}+$ urea, $\mathrm{T}_{9^{-}}$ Biourea and $\mathrm{T}_{10^{-}}$Nanobiourea. Equal amount of each adsorbents (zeolite, nanozeolite, biochar and size reduced biochar) plus urea (1:1 ratio) were physically mixed separately and the fine powder samples were produced by ground and homogenized for VAL rate determination. Fertilizers were placed on surface @ $250 \mathrm{~kg} \mathrm{ha}^{-1}$ and tested as completely randomized block design of three replications. Experimental chamber setup was similar to soil respiration studies (Alef, 1995). Air-dried soils were crushed and passed through

Table 1. Characteristics of the experimental soils used in study.

\begin{tabular}{lcc}
\hline Properties & Bhavanisagar loam soil & Coimbatore black soil \\
\hline Soil Order & Alfisols & Inceptisols \\
Textural Composition & & 42 \\
Clay (\%) & 15.6 & 14.7 \\
Silt $(\%)$ & 6.2 & 16.2 \\
Fine sand (\%) & 44 & 21.6 \\
Coarse sand (\%) & 31 & Clayey \\
Textural class & Loamy sand & 8.52 \\
pH $(1: 2.5)$ & 8.4 & 0.2 \\
EC $\left(\mathrm{dSm}^{-1}\right)$ & 0.06 & 23.2 \\
CEC $\left(\mathrm{cmol}^{+}\left(\mathrm{p}^{+}\right) \mathrm{kg}^{-1}\right)$ & 10.9 & 19.8 \\
Urease activity $\left(\mathrm{mg} \mathrm{g}^{-1} \mathrm{~h}^{-1}\right)$ & 13.2 & 1.44 \\
Bulk Density $\left(\mathrm{gcm}^{-3}\right)$ & 1.62 & 2.65 \\
Particle Density $\left(\mathrm{gcm}^{-3}\right)$ & 2.61 & 52.3 \\
Porespace $(\%)$ & 32.1 & 47.3 \\
Water holding capacity $(\%)$ & 27.9 & 0.09 \\
Total nitrogen $(\%)$ & 0.03 & 4200 \\
Organic carbon $\left(\mathrm{mg} \mathrm{kg}^{-1}\right)$ & 3420 & 154 \\
Available nitrogen $\left(\mathrm{kg} \mathrm{ha}^{-1}\right)$ & 148 & 20 \\
Available phosphorus $\left(\mathrm{kg} \mathrm{ha}^{-1}\right)$ & 35 & 638 \\
Available potassium $\left(\mathrm{kg} \mathrm{ha}^{-1}\right)$ & 907 & \\
\hline
\end{tabular}


Table 2. Evaluation of ammonia volatilization loss on urea fertilizer formulations.

\begin{tabular}{lcc}
\hline \multirow{2}{*}{ Fertilizer type } & \multicolumn{2}{c}{ Volatilization (days) } \\
\cline { 2 - 3 } & Alfisols & Inceptisols \\
\hline $\mathrm{T}_{1}$ - Control* & $\mathrm{NA}$ & $\mathrm{NA}$ \\
$\mathrm{T}_{2}$ - Urea & 5.5 & 4.6 \\
$\mathrm{~T}_{3}$ - Zeolite + Urea & 8.5 & 9.4 \\
$\mathrm{~T}_{4}$ - Nanozeolite + Urea & 11 & 12.1 \\
$\mathrm{~T}_{5}$ - Zeourea & 13.5 & 15.1 \\
$\mathrm{~T}_{6}$ - Nanozeourea & 15.5 & 16 \\
$\mathrm{~T}_{7}$ - Biochar+ Urea & 6 & 6.8 \\
$\mathrm{~T}_{8}$ - SRB + Urea & 6 & 6 \\
$\mathrm{~T}_{9}$ - Biourea & 7.5 & 7.1 \\
$\mathrm{~T}_{10}$ - Nanobiourea & 9 & 9.7 \\
$\mathrm{SEd}$ & 1.11 & 0.88 \\
$\mathrm{CD}(0.05)$ & 2.34 & 1.86 \\
\hline
\end{tabular}

*NA-Not observed

$2 \mathrm{~mm}$ sieve. A $150 \mathrm{~g}$ soil from each location was weighed and spread into a $4.5 \mathrm{~cm}$ of height in $250 \mathrm{ml}$ schott duran bottle (Length-14.5 cm). Inside a closed bottle, $10 \mathrm{ml}$ of $2 \%$ boric acid with double indicator solution (Height $-2.7 \mathrm{~cm}$ ) were taken in $(15 \mathrm{ml})$ qualigens vial. In order to maintain optimum moisture content and induce urea hydrolysis, @ 5 ml of distilled water was poured and for aeration opened for 2 minutes per day. The trapped ammonia was observed for colour change from pink to greenish as indicator (Kumar and Tarafdar, 2011). The volatilized ammonia was determined upto 16 days. Beyond this the colour changes were not observed. Absorbed ammonia was titrated with $0.02 \mathrm{~N} \mathrm{H}_{2} \mathrm{SO}_{4}$. The data were subjected to cumulative VAL rate expressed in percentage and statistical analysis $(\mathrm{P}=0.05)$ done by least significant difference (LSD) as per Panse and Sukhatme (1985) and control treatment excluded due to ammonia volatilization was not observed on the study period.

\section{RESULTS AND DISCUSSION}

The results of incubation experiment explained that the ammonia volatilization was highly varied and mean data of two different soils (Table 2). Ammonia volatilization was observed from 5-16 days of experimental period. The first three days volatilization was high on $\mathrm{T}_{2^{-}}$Urea and physically mixed adsorbent fertilizers than on urea impregnated fertilizers. Initial 3 days of colour change was observed on every 4-6 $\mathrm{h}$ on $\mathrm{T}_{2^{-}}$ Urea and physically mixed adsorbent fertilizers of both soils. In contrast, the urea impregnated fertilizers had colour change after 9-10 h regardless of adsorbent and soil. After the completion of third day, colour change was observed after 11-12 $\mathrm{h}$ and 14-16 $\mathrm{h}$ of frequency on physically mixed adsorbent fertilizers and impregnated fertilizers respectively. All four physically mixed fertilizers maximum VAL rate was recorded on second day irrespective of soil texture while impregnated fertilizer formulations delayed the VAL rate on third and fourth day of micro and nano sized adsorbents on both soil textures. VAL occurred up to days were men-

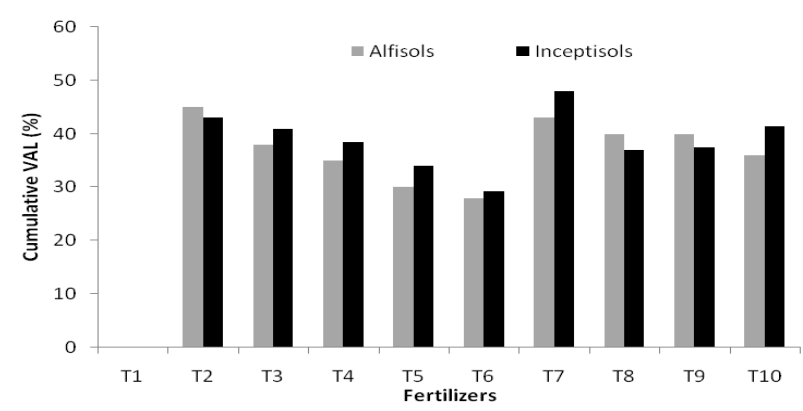

Fig. 1.Cumulative volatilized ammonia loss rate (\%) of soils.

tioned in parenthesis. The fabricated fertilizer observed volatilization gradually with low quantity on $\mathrm{T}_{5^{-}}$ Zeourea (13.5, 15.1 days), $\mathrm{T}_{6}$ - Nanozeourea $(15.5,16$, days), $\mathrm{T}_{9^{-}}$Biourea $\left(7.5,7.1\right.$ days) and $\mathrm{T}_{10^{-}}$Nanobiourea (9, 9.7 days), than $\mathrm{T}_{2^{-}}$- Urea (5.5, 4.6 days) of Alfisols and Inceptisols respectively. Volatilization loss of ammonia from urea had influenced the efficiency of urea. Similar findings were recorded in sandy clay loam soil experiment conducted at Indian Agricultural Research Institute, New Delhi on blending of iron pyrite with urea and nil ammonia volatilization on first day (Blaise and Prasad, 1995). Maximum $\mathrm{NH}_{3}$ loss occurred at seven days after urea-zeolite mixture was applied to an alkaline soil (He et al., 2002). Use of green waste biochar for rehabilitation of bauxiteprocessing residue sand at Australia confirmed the adsorption of ammonium in $\mathrm{pH} 7$ and 8 and reduced the cumulative ammonia volatilization rate (Chen et al., 2013).

Ammonia volatilization did not occur in $\mathrm{T}_{1}$ - Control (soil alone) on both soil textures during the period of study and cumulative VAL rate percentage (Fig. 1.) of $\mathrm{T}_{2-}$ Urea (5.5 days with $45 \%$ ) and (4.6 days with 43 $\%)$ loss was recorded of Alfisols and Inceptisols, respectively. Ammonium loss percentage was low on $\mathrm{T}_{5^{-}}$ zeourea $(30,34 \%)$ and $\mathrm{T}_{6}$ - Nanozeourea $(28,29.3 \%)$, $\mathrm{T}_{9^{-}}$Biourea $(39,37.5 \%), \mathrm{T}_{10^{-}}$Nanobiourea $(36,37.5$ $\%$ ) of alfisols and inceptisols, respectively on comparison with other fertilizer type. The least cumulative VAL rate percentage was observed on impregnated fertilizers $\mathrm{T}_{6}$ - Nanozeourea (15.5 days, $28 \%$ ) and (16 days, $29.3 \%$ ), $\mathrm{T}_{10^{-}}$Nanobiourea (9 days and $36 \%$ ) and (9.7 days, $37.5 \%$ ) of alfisols and inceptisols respectively. Since, nano zeolite had high surface area and selective adsorption and affinity for ammonium, the volatilization loss of $\mathrm{N}$ was maintained lower in comparison to other formulations. The presence of micro and nanopores in nanozeolite and size reduced biochar (small internal tunnels) had found to physically protect ammonium ion from excessive nitrification by micro-organisms. High longevity of biochar adsorbed ammonia. Modifying the acidic functional groups of carbon and more than $79 \%$ adsorption sites for ammonium in nanozeolite, size reduced biochar, $\mathrm{pH}$ reduction, poor microbial population and delay conversion of ammonium to ammonia. Adsorbent's 
internal tunnels act as shelter and slow and continuous volatilization on both the soils may use the micro sites and thereby minimizing the loss , and use of $10 \%$ polymer on impregnation also helped to delay VAL rate. Similar results were shown by calcareous sandy soil at FL, USA by cellulose plus clinoptilolite zeolite with three nitrogenous fertilizers (Ammonium nitrate, ammonium sulphate and urea) (He et al., 2002) and at Temuka, New zealand a silt loam soil plus ruminant urine with different dose of biochar $\left(0,15,30 \mathrm{tha}^{-1}\right)$ was reduced $45 \%$ ammonia volatilization (Toosi et al., 2012) and other experiments explained that ammonia volatilization reduced on use of biochar on composting. In a similar study, maximum $\mathrm{NH}_{3}$ loss of the treatments occurred on the third day of incubation after which there was a general decline until day 15 when the $\mathrm{NH}_{3}$ loss was about $1 \%$ of the $\mathrm{N}$ added as urea-zeolite in acid sulphate soil (Ahmed et al., 2010). Kim et al. (2011) reported that intercalation of montmorillonite and urea suppressed rate of ammonia volatilization on first day and also lead to a decrease in its peak emission rate (up to $288 \mathrm{~h}$ ) in sandy loam soil at Chilgokgun, Korea. Zeolite and urea liquid mixing reduced ammonia loss and improved retention than granular urea in sandy clay loam soil at Malaysia (Bundan et al., 2011). Zeolite and urea addition with organic binder reduced ammonia volatilization by 20 percent in sandy soils of Seropedica, Rio de Janeiro (Werneck et al., 2012). High rate of adsorption pattern of ammonium was recorded on aged biochar and reduced rate of ammonia volatilization in bauxiteprocessing residue sand at Australia (Chen et al., 2013). Our study explained the use of the (urea impregnation with adsorbents) fabricated fertilizers and physical mixing to mitigate ammonia volatilization loss rate with cumulative VAL percentage in Inceptisols and Alfisols soils.

\section{Conclusion}

Physical mixing of urea plus adsorbents did not influence VAL rate whereas urea impregnated micro or nano sized adsorbents (fabricated fertilizers) delayed VAL rate on surface application in Alfisols and Inceptisols soils under laboratory conditions which should be studied further in field to confirm resulting pattern. Our study elucidates that micro and nano porous adsorbents are potential substrate to reduce VAL rate percentage.

\section{ACKNOWLEDGMENTS}

The authors gratefully acknowledge GOI and UGC, New Delhi for Ph. D. fellowship award (2010-12) and financial support under the "Smart Delivery of nitrogen in plant system through nano-fertilizers". Special thanks to Mr. M. Thangavel for the assistance on analytical part of the study.

\section{REFERENCES}

Ahmed, O. H., Yap, C. B. and Muhamad, A. N. (2010). Minimizing ammonia loss from urea through mixing with zeolite and acid sulphate soil. International Journal of Physical Sciences, 5(14): 2198-2202

Alef, K. 1995. Soil Respiration. Kassem Alef and Paolo Nannipieri (eds.), Methods in Applied Soil Microbiology and Biochemistry, Elsevier, 214-219

Bishop, P. and Manning, M. (2010). Urea volatilisation: the risk management and mitigation strategies. In 'Adding to the knowledge base for the nutrient manager. Proceedings $24^{\text {th }}$ Annual FLRC Workshop'. Eds LD Currie, CL Christensen. Fertilizer and Lime Research Centre, Massey University. Palmerston North, New Zealand Pp. $1-13$

Blaise, D. and Prasad, R. (1995). Effect of blending urea with pyrite or coating urea with polymer on ammonia volatilization loss from surface-applied prilled urea. Biology and fertility of soils, 20(1): 83-85

Bundan, L., Majid, N. M. A., Ahmed, O. H., Jiwan, M. and Kundat, F. R. (2011). Ammonia volatilization from urea at different levels of zeolite. International Journal of Physical Sciences, 6(34): 7717-7720

Cameron, K. C., Di, H. J. and Moir, J. L. (2013). Nitrogen losses from the soil/plant system: a review. Annals of Applied Biology, 162(2): 145-173

Chang, H. J. (1997). Method of preparing a slow release fertilizer. US Patent 5695542, Dec 9.1997.

Chen, C. R., Phillips, I. R., Condron, L. M., Goloran, J., Xu, Z. H. and Chan, K. Y. (2013). Impacts of greenwaste biochar on ammonia volatilisation from bauxite processing residue sand. Plant and soil, 367(1-2): 301-312

Fan, X. H., Li, Y. C. and Alva, A. K. (2011). Effects of temperature and soil type on ammonia volatilization from slow-release nitrogen fertilizers. Communications in soil science and plant analysis, 42(10): 1111-1122

He, Z. L., Calvert, D. V., Alva, A. K., Li, Y. C. and Banks, D. J. (2002). Clinoptilolite zeolite and cellulose amendments to reduce ammonia volatilization in a calcareous sandy soil. Plant and Soil, 247(2): 253-260

Kim, K. S., Park, M., Choi, C. L., Lee, D. H., Seo, Y. J., Kim, C. Y., Kim, J. S., Yun, S. I., Ro, H. M. and Komarneni, S. (2011). Suppression of $\mathrm{NH}_{3}$ and $\mathrm{N}_{2} \mathrm{O}$ emissions by massive urea intercalation in montmorillonite. Journal of Soils and Sediments, 11(3): 416-422

Kumar, P. and Tarafdar, J. C. (2011). Effect of urea on availability of micronutrients in arid soils. Journal of the Indian Society of Soil Science, 59(2): 148-157

Latifah, O., Ahmed, O. H. and Muhamad, A. N. (2011). Ammonia loss, ammonium and nitrate accumulation from mixing urea with zeolite and peat soil water under waterlogged condition. African Journal of Biotechnology, 10(17): 3365-3369

Manikandan, A. and Subramanian, K. S. (2014). Fabrication and characterisation of nanoporous zeolite based $\mathrm{N}$ fertilizer. African Journal of Agricultural Research, 9(2): 276-284

Manikandan, A., Subramanian, K.S. and Pandian, K. (2013). Effect of high energy ball milling on particle size and surface area of adsorbents for efficient loading of fertilizer. An Asian Journal of Soil Science. 8(2): 249-254

Nascimento, C.A.C.D., Vitti, G.C., Faria, L.D.A., Luz, P. H. 
C. and Mendes, F.L. (2013). Ammonia volatilization from coated urea forms. Revista Brasileira de Ciência do Solo, 37(4): 1057-1063

Paiva, D. M. D., Cantarutti, R. B., Guimarães, G. G. F. and Silva, I. R. D. (2012). Urea coated with oxidized charcoal reduces ammonia volatilization. Revista Brasileira de Ciência do Solo, 36(4): 1221-1230

Panse, V.G. and Sukhatme, P.V. (1985). Statistical Methods for Agricultural Workers. ICAR Publications, New Delhi, 1-21.

Rui, Z., YuBao, Z., Yagi, K., Hosen, Y., XiaoHong, X. and ZhiJie, L. (2010). The effect of coated urea on $\mathrm{N}$ use efficiency and ammonia volatilization. JIRCAS Working Report, (65): 13-17

Stafanato, J. B., Goulart, R. D. S., Zonta, E., Lima, E., Mazur, N., Pereira, C. G. and Souza, H. N. D. (2013). Ammonia volatilization from pelletized urea with micronutrients in a controlled environment. Revista Brasileira de Ciência do Solo, 37(3): 726-732

Tandon, H. L. S. (2005). Methods of analysis of soils, plants, waters, fertilizers \& organic manures. Fertiliser Development and Consultation Organisation, New Delhi.

Toosi, A. T., Clough, T. J., Sherlock, R. R. and Condron, L. M. (2012). A wood based low-temperature biochar captures $\mathrm{NH}_{3}-\mathrm{N}$ generated from ruminant urine-N, retaining its bioavailability. Plant and Soil, 353(1-2): 73-84

Werneck, C. G., Breda, F. A., Zonta, E., Lima, E., Polidoro, J. C., Balieiro, F.D.C. and Bernardi, A.C.D.C. (2012). Ammonia volatilization from urea with natural zeolite. Pesquisa Agropecuária Brasileira, 47(3):466-470

Zabochnicka S.M. and Malińska, K. (2010). Removal of ammonia by clinoptilolite. Global NEST Journal, 12(3): 256-261 